\title{
The role of mutual in-feeding in maintaining problematic self-narratives: Exploring one path to therapeutic failure
}

\author{
MIGUEL M. GONÇALVES ${ }^{1}$, ANTÓNIO P. RIBEIRO ${ }^{1}$, WILLIAM B. STILES ${ }^{2}$,

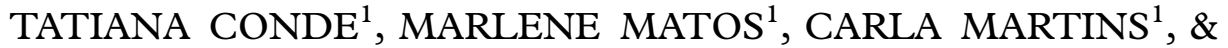 \\ ANITA SANTOS ${ }^{3}$ \\ ${ }^{1}$ School of Psychology, University of Minho, Braga, Portugal; ${ }^{2}$ Department of Psychology, Miami University, Oxford, Ohio, \\ USA $\mathcal{E}^{3}$ ISMAI, Maia, Portugal
}

(Received 10 February 2010; revised 1 fune 2010; accepted 7 fuly 2010)

\begin{abstract}
According to the author's narrative model of change, clients may maintain a problematic self-stability across therapy, leading to therapeutic failure, by a mutual in-feeding process, which involves a cyclical movement between two opposing parts of the self. During innovative moments (IMs) in the therapy dialogue, clients' dominant self-narrative is interrupted by exceptions to that self-narrative, but subsequently the dominant self-narrative returns. The authors identified return-to-the-problem markers (RPMs), which are empirical indicators of the mutual in-feeding process, in passages containing IMs in 10 cases of narrative therapy (five good-outcome cases and five poor-outcome cases) with females who were victims of intimate violence. The poor-outcome group had a significantly higher percentage of IMs with RPMs than the good-outcome group. The results suggest that therapeutic failures may reflect a systematic return to a dominant self-narrative after the emergence of novelties (IMs).
\end{abstract}

Keywords: process research; narrative; mutual in-feeding; innovative moments

Why don't people change? Each therapy model has an account: "Resistance. Reactance. Noncompliance. Unfinished business. Whatever you call it, we all have had to deal with ambivalence to change in our clients" (McCarthy \& Barber, 2007, p. 504). This article explores one possible path to therapeutic failure: how problematic self-stability can be maintained, throughout therapy, by a mutual in-feeding process (Valsiner, 2002), a cyclical movement between two opposing parts of the self: the client's dominant self-narrative (usual way of understanding the world) and innovative moments ${ }^{1}$ (IMs; M. M. Gonçalves, Matos, \& Santos, 2009; M. M. Gonçalves, Santos, et al., 2010), which are moments in the therapeutic dialogue when clients challenge their dominant self-narrative. We investigated mutual in-feeding in 10 cases of narrative therapy (five good-outcome cases and five pooroutcome cases) with women who were victims of intimate violence, previously analyzed with the innovative moments coding system (IMCS; M. M. Gonçalves, Ribeiro, Matos, Mendes, \& Santos, 2010a; M. M. Gonçalves, Ribeiro, Matos, Mendes, \& Santos 2010b) by Matos, Santos, M. M. Gonçalves, and Martins (2009).

\section{Dominant Self-Narratives and IMs}

Recent empirical studies of IMs' development in psychotherapy have led to a narrative model of change, which suggests that change in psychotherapy occurs through the emergence and amplification of different types of IMs (M. M. Gonçalves, Mendes, Ribeiro, Angus, \& Greenberg, 2010; Matos et al., 2009; Mendes, Ribeiro, Angus, Greenberg, Sousa, \& M. M. Gonçalves, in press; Ribeiro, M. M. Gonçalves, \& Santos, in press; Santos, M. M. Gonçalves, Matos, \& Salvatore, 2009; Santos,

Correspondence concerning this article should be addressed to Miguel M. Gonçalves, School of Psychology, University of Minho, Braga 4710, Portugal. Email: mgoncalves@psi.uminho.pt 
M. M. Gonçalves, \& Matos, 2010). According to this theory, a self-narrative may manifest itself as implicit rules the person feels bound to follow or as constraints on the way he or she experiences the world (see White, 2007; White \& Epston, 1990; Zimmerman \& Dickerson, 1994), insofar as a selfnarrative "not only governs which meanings are attributed to events, but it also selects which events are included and which are left out of the story" (Polkinghorne, 2004, p. 58). Therefore, a selfnarrative maintains the person's way of understanding the world, triggering repetition and fostering stability and expectedness in dealing with the uncertainty of the future (Josephs \& Valsiner, 1998).

Hermans and Hermans-Jansen (1995) have suggested that self-narratives result not from the activity of an omniscient narrator (equated with the self) but from a dialogical process of negotiation, tension, disagreement, and alliance among different internal positions or voices. Congruently, according to the assimilation model (Honos-Webb \& Stiles, 1998; Stiles, 1999, 2002; Stiles et al., 1990), such internal voices represent traces of individuals' experiences or ways of being in the world. The voice metaphor underscores the traces' agency; they can speak and act. Constellations of similar or related experiences become linked, or assimilated, and form a community of voices. The community is experienced by the individuals as their usual sense of self, personality, or center of experience. The voice that is most often speaking is normally a member of this dominant community of voices and is sometimes called a "dominant voice."

We suggest that people become vulnerable to distress and are likely to present for therapy if their dominant community of voices is bound together by a self-narrative that is too rigid and systematically excludes significant experiences because they are not congruent with it. From the community's perspective, voices representing experiences that are discrepant from how individuals typically perceive themselves are problematic, and the community of voices wards off, distorts, or actively avoids such voices (Stiles, 1992, 2002; Stiles, Osatuke, Glick, \& Mackay, 2004). Although such avoidance can prevent or reduce the distress in the short term, the experiences remain unassimilated and unavailable as resources, so from a clinician's perspective, the dominant self-narrative is problematic. In previous work, we have often used the term problematic selfnarrative to refer to clients' dominant self-narrative. In this article, however, we prefer to characterize these self-narratives by their role in binding the community together rather than by their value from an external perspective, although indeed the dominant self-narratives we chose to study seemed problematic from our perspective. Unassimilated voices are not inert or devoid of agency. They may be silenced and excluded, but circumstances (including the therapeutic dialogue) may address them, impelling them to move from the background to the foreground (Hermans, 2006; Stiles et al., 2004) and producing IMs. When they emerge during IMs, such unassimilated voices challenge the dominant self-narrative. Dialogically, then, IMs are opportunities for unassimilated voices to emerge and to tell their own stories, which differ from the ones told by the dominant community.

The logic of IMs is illustrated by a recent study by Osatuke and Stiles (2010; see also Osatuke et al., 2007), which found a common dialogical pattern in depressive clients: a conflict between an interpersonally submissive but intrapersonally dominant voice, which organizes the majority of experiences (being the dominant narrator), and an autonomous and interpersonally assertive voice that is intrapersonally suppressed by the community of voices that constitutes the self. An IM would be considered as occurring every time the assertive voice was somehow heard, regardless of whether it emerged as a thought, action, wish, or feeling. For the dominant voice in such depressive cases, the process of rejecting and silencing other voices maintains a dominant self-narrative characterized by rigidity and redundancy. Such dominant self-narratives comprise strict rules, such as "always privilege the wishes of others and ignore your own." All voices that suggest otherwise are excluded, suppressed, or avoided, creating tension because they are not being heard. Thus, for instance, when the person faces a conflict with others and decides not to be assertive, a tension is created because the nondominant (but assertive) voices fight to be heard. Hearing from a nondominant voice constitutes a novelty in the selfsystem, which we call an IM. As a nondominant voice is assimilated in the course of successful therapy, it becomes more accessible and less dissociated from the community of voices, and the rigidity and redundancy of the dominant selfnarrative decrease.

\section{Types of IMs and Associations with Outcome}

The IMCS distinguishes five types of IMs that have been observed in the therapeutic process: action, reflection, protest, reconceptualization, and performing change (M. M. Gonçalves, Ribeiro, et al., 2010a, 2010b, in press; M. M. Gonçalves, Santos, et al., 2010; M. M. Gonçalves, Mendes, et al., 2010; Matos et al., 2009; Mendes et al., in press; Ribeiro et al., in press; Santos et al., 2010). 
Action IMs are specific behaviors that challenge the dominant self-narrative.

Reflection IMs are thoughts, feelings, intentions, projects, or other cognitive products that challenge the dominant self-narrative.

Protest IMs entail new behaviors (like action IMs) and/or thoughts (like reflection IMs) that challenge the dominant self-narrative, representing a refusal of its assumptions. This active refusal is the key feature that allows distinguishing protest from action and reflection.

Reconceptualization IMs are the most complex type of innovations. The client not only describes some form of contrast between present and past (e.g., "Now I've changed $X$ or $Y$ ") but also understands the processes that allowed this transformation.

Performing change IMs (previously labeled as new experiences) are new aims, experiences, activities, or projects, anticipated or in action, as a consequence of change.

Examples of these IMs are shown in Table I. IMs can be coded from transcripts and audio or video recordings of sessions. While coding IMs, coders must keep in mind the main features of the dominant self-narrative - the constraining rulesin order to identify the exceptions to those rules (i.e., the IMs).

Studies of brief psychotherapy have shown that poor- and good-outcome cases have different profiles of IMs. Two relevant, replicated findings have been observed in hypothesis-testing studies (Matos et al., 2009; Mendes et al., in press) and case studies (M. M. Gonçalves, Mendes, et al., 2010; Ribeiro et al., in press; Santos et al., 2010). First, IMs appear in both poor- and good-outcome cases, although in good-outcome cases their salience ${ }^{2}$ (i.e., the time devoted to the elaboration of IMs calculated as a percentage of the session) is greater and tends to increase as the treatment develops. Second, reconceptualization and performing change IMs are seldom observed in poor-outcome cases but represent a substantial percentage of the IMs observed in goodoutcome cases. In good-outcome cases, reconceptualization IMs tend to occur in the middle of the therapeutic process and increase until the end. Performing change IMs tend to occur after the development of reconceptualization. Hence, poorand good-outcome cases tend to be similar at the beginning of treatment, but in good-outcome cases action, reflection, and protest IMs progress to reconceptualization and performing change in the middle and later parts of treatment.

\section{IMs and Problematic Self-Stability: Mutual In-Feeding}

What processes block the path of successful psychotherapy in poor-outcome cases? Why do pooroutcome cases fail to follow the pattern of increasing IM salience and the evolution from action, reflection, and protest IMs to reconceptualization and performing change IMs in the middle and late phases of therapy?

We argue, along with Hayes, Laurenceau, Feldman, Strauss, and Cardaciotto (2007), that "therapy provides a stable environment and increases patients' readiness and resources for change, but it also introduces a variety of interventions to interrupt, challenge, and destabilize" (p. 717). The emergence and elaboration of IMs in the therapeutic conversation challenges and destabilizes a person's usual way of understanding and experiencing (the dominant self-narrative), generating a sense of discrepancy or inner contradiction (M. M. Gonçalves \& Ribeiro, in press; Ribeiro \& M. M. Gonçalves, 2010). Congruently, Engle and collaborators (Engle \& Arkowitz, 2008; Engle \& Holiman, 2002) have emphasized, from a humanistic-experiential perspective, that psychological changes introduce discrepancy or inner contradiction. This discrepancy may be experienced as a threat, evoking a self-protective response in which the discrepant experience is "distorted, denied, or inadequately symbolized," keeping the client safe from the anxiety produced by the change (Engle \& Arkowitz, 2008, p. 391). Hence, IMs represent a window of opportunity for developing a new selfnarrative, but they may also create unpredictability and uncontrollability (Arkowitz \& Engle, 2007), threatening clients' sense of self-stability. Whether IMs develop into a new self-narrative depends on the way this threat is managed.

We have noticed that in poor-outcome cases (Santos et al., 2010), as well as in initial and middle phases of good-outcome cases (Ribeiro et al., in press), clients tend to resolve the discrepancies or inner contradictions that characterize IMs by making a quick return to the dominant self-narrative. As Swann (1987) suggested, self-discrepant information (IMs) may prompt people to retrieve information supporting the self-conception that is being contradicted, thus promoting the return to the dominant self-narrative.

The return to the dominant self-narrative suppresses the innovative way of feeling, thinking, or acting, by bypassing, minimizing, depreciating, or trivializing its meaning, and reinstates the dominant self-narrative, promoting stability. Clients thereby avoid the sense of discrepancy or inner contradiction. As this sequence repeats, clients oscillate between 
Table I. Examples of Innovative Moments Vis-à-Vis a Depressive Dominant Self-Narrative

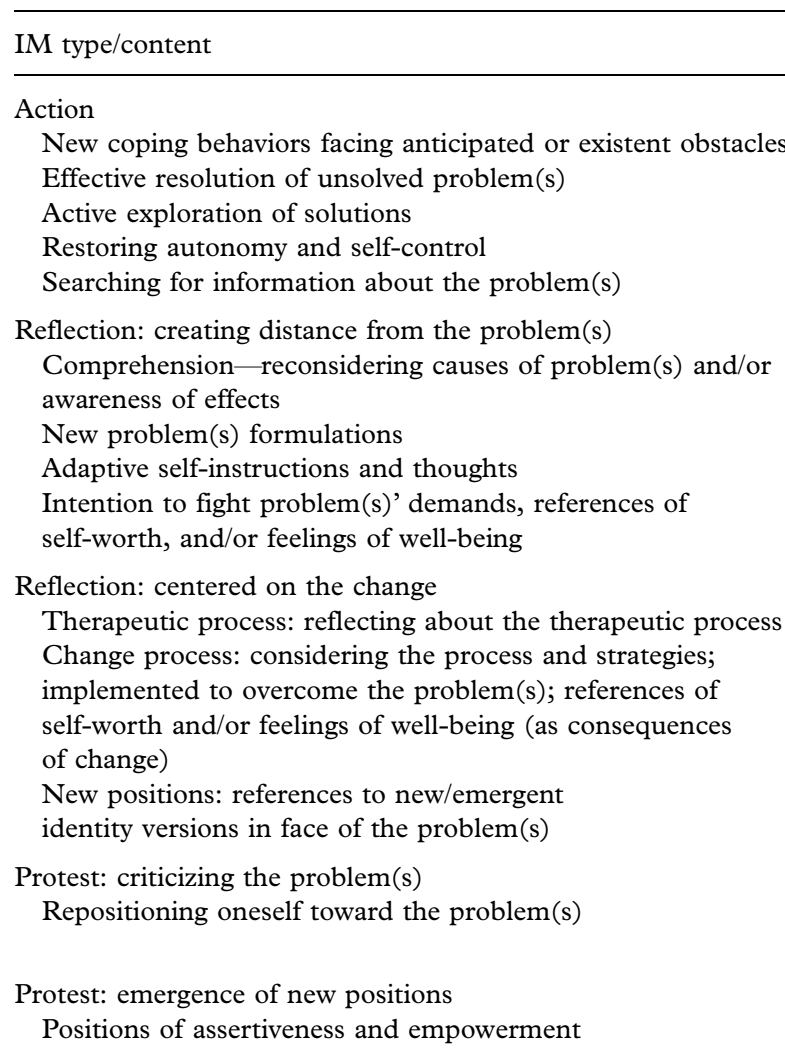

Reconceptualization

Always involve two dimensions: (1) description of the shift between two positions (past and present) and

(2) the process underlying this transformation
C: I realize that what I was doing was just, not humanly possible because I was pushing myself and I never allowed myself any free time, uh, to myself ... and it's more natural and more healthy to let some of these extra activities go.

C: I believe that our talks, our sessions, have proven fruitful, I felt like going back a bit to old times, it was good, I felt good, I felt it was worth it.

C: What am I becoming after all? Is this where I'll be getting to? Am I going to stagnate here!?

C: I am an adult and I am responsible for my life, and, and, I want to acknowledge these feelings and I'm going to let them out! I want to experience life, I want to grow and it feels good to be in charge of my own life.

C: You know ... when I was there at the museum, I thought to myself, "You really are different ... A year ago you wouldn't be able to go to the supermarket!" Ever since I started going out, I started feeling less depressed ... it is also related to our conversations and changing jobs.

T: How did you have this idea of going to the museum?

C: I called my Dad and told him, "We're going out today!"

T: This is new, isn't it?

C: Yes, it's like I tell you ... I sense that I'm different.

T: You seem to have so many projects for the future now!

C: Yes, you're right. I want to do all the things that were impossible for me to do while I was dominated by depression. I want to work again and to have the time to enjoy my life with my children. I want to have friends again. The loss of all the friendships of the past is something that still hurts me really deeply. I want to have friends again, to have people to talk to, to share experiences and to feel the complicity in my life again. elaboration of IMs, which temporarily disrupts the dominant narrative, and the return to the dominant self-narrative, reducing the discrepancy created by the innovation. In this repetitive process, expressions of the dominant self-narrative and IMs expressing an alternative self-narrative act as opposite self-positions in a negative feedback loop relation (Figure I). Valsiner (2002) has called this process "mutual infeeding."

Mutual in-feeding is thus a form of stability within the self, which may be understood as two opposing parts of the self that keep feeding into each other, 


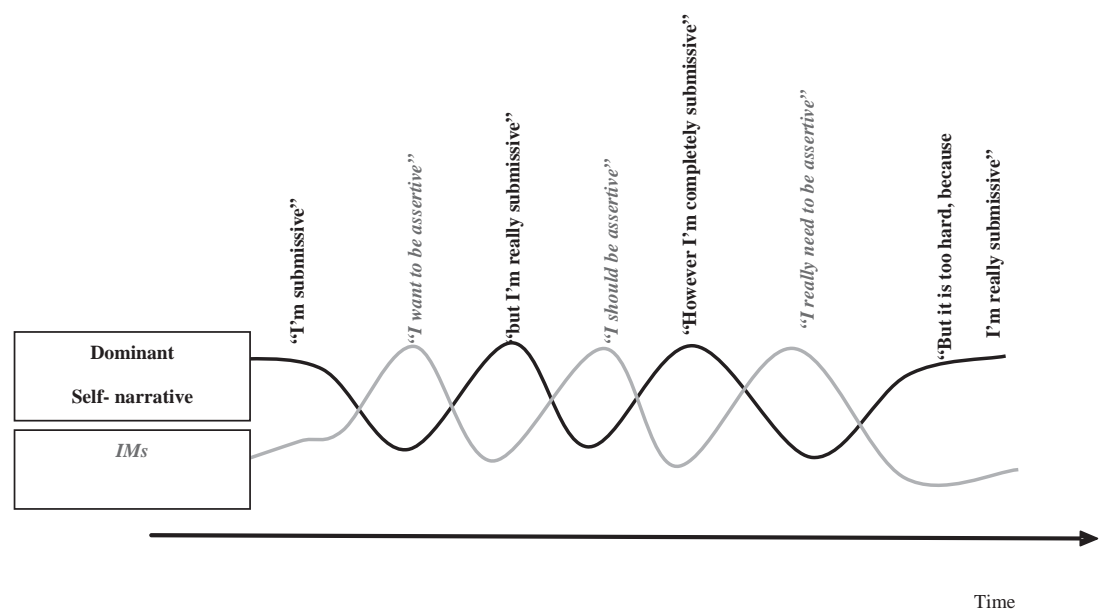

Figure I. Mutual in-feeding throughout the therapeutic process.

expressing themselves alternately. From a dialogical point of view (Valsiner, 2002; see also Hermans, 1996), the client performs a cyclical movement between a voice (dominant self-narrative) and a countervoice (alternative self-narrative) that interferes with the development of an inclusive system of meanings in therapy in which these internal voices respectfully listen to each other and engage in joint action.

As an illustration, imagine that one of the submissive, depressed clients studied by Osatuke and Stiles (2010) said, "Sometimes I say to myself: I won't do $X$ [something requested explicitly or implicitly by others]." This assertive expression would constitute an IM, because it is a challenge of the dominant self-narrative. This innovative voice might be neutralized if a dominant voice emerged and said something like "But then I feel I'm being an egotistical person in not doing $X$." If this dominant voice forces again the nondominant (innovative) voice to the background and silences it, neutralization of the novelty has occurred (Figure II).

Mutual in-feeding may lead to an "impasse or a state of 'stuckness"' (Honos-Webb \& Stiles, 1998, p. 28; cf. Perls, 1969); however, this may be overcome by the development of relationships between the two opposing voices as they build meaning bridges (Brinegar, Salvi, Stiles, \& Greenberg, 2006; Osatuke et al., 2004; cf. Rice \& Saperia, 1984). A meaning bridge is a sign or system of signs (e.g., word, phrase, gesture, or narrative) that has the same meaning to the author and addressee (e.g., an unassimilated voice and the community of voices). Meaning bridges enable voices to communicate about shared experiences and form links to each other. By building meaning bridges, previously avoided experiences may become accessible to the community as resources following a developmental progression described in the assimilation of problematic experiences sequence (APES; Stiles, 2002; Stiles et al., 1990).

Mutual in-feeding is congruent with a variety of other formulations of clients' resistance to psychotherapeutic change (Arkowitz \& Engle, 2007; Feixas, Sánchez, \& Gómez-Jarabo, 2002). With Arkowitz and Engle (2007), we understand resistance as ambivalence. Within a multivoiced understanding of the self, clients who are ambivalent possess an internal voice that moves toward change and another internal voice that struggles against change. Congruent with this formulation, the assimilation model's concept of "rapid cross-fire" refers to opposing expressions by two contradictory internal voices (Brinegar et al., 2006); each voice triggers contradiction by the other, so they seem "to fight for possession of the floor" (Brinegar et al., 2006, p. 170). A similar formulation is constructivist therapy's concept of "slot rattling" (Kelly, 1955), in which clients construe experiences on the opposite pole of an existing construct. For example, a pessimistic person might act as if he or she was an optimistic person. If pursued, this could lead to beneficial elaboration of the person's construct system, enabling further development. More often, however, slot rattling is only superficial movement, with the client reverting to the original pessimism when he or she encounters difficulties or invalidation. In each of these characterizations of conflicting internal self-positions, the dialogue maintains the person's status quo. They seem to reflect efforts to protect self-identity, sense of integrity, or coherence (Ecker \& Hulley, 2000; Feixas et al., 2002; Fernandes, Senra, \& Feixas, 2010; Kelly, 1955; Mahoney, 1991). 


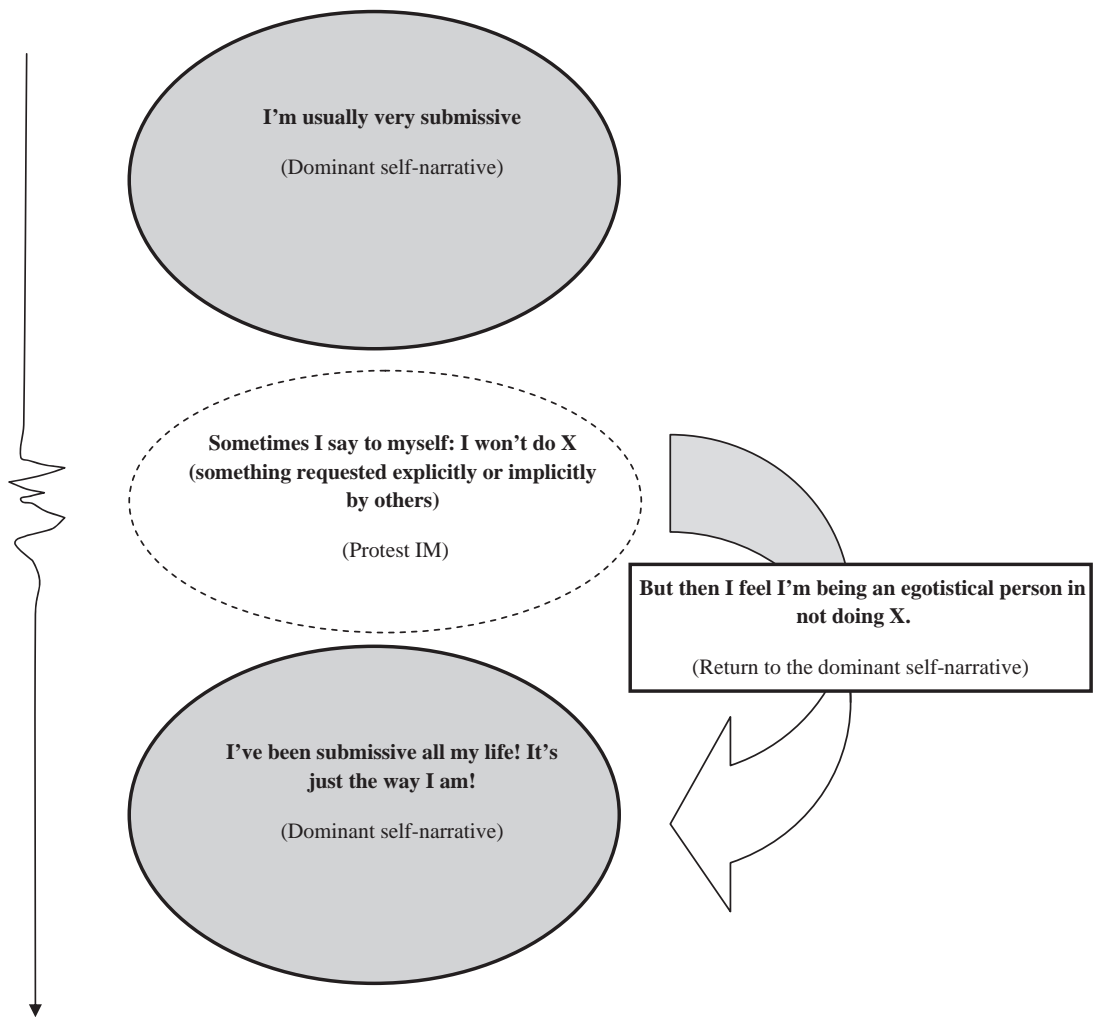

Figure II. Avoiding self-discrepancy by returning to the dominant self-narrative.

\section{The Return-to-the-Problem Marker}

We propose a measure of the mutual in-feeding process that grew from our observations of therapy passages in which an IM emerged and was immediately followed by a return to the dominant self-narrative. We call such an event a "returnto-the-problem" marker (RPM). Take, for example, the following:

I don't want to be depressed anymore. [Reflection IM]

\section{But I just can't. [RPM]}

In this example, the IM 'I don't want to be depressed anymore" was followed by a return to the dominant self-narrative, "but I can't." This clause introduced by the word but represents opposition or negation toward what is being said and constitutes the RPM.

\section{Goals and Hypotheses}

Our goal was to shed light on problematic selfstability. We sought to assess whether clients' responding to IMs by returning to the dominant self-narrative (i.e., responding with RPMs) contributes to maintaining the dominant self-narrative.
We expected that in poor-outcome cases the potential for IMs to create narrative diversity would be prevented by the rapid return to the dominant self-narrative (Santos \& M. M. Gonçalves, 2009; Santos et al., 2010). In good-outcome cases, on the other hand, IMs should be elaborated, with relatively fewer RPMs, at least in the later stages of therapy (Ribeiro et al., in press). Further, reconceptualization IMs and performing change IMs, which tend to occur in the late stages of good-outcome cases, seem less likely than other IMs to support RPMs. Reconceptualization "requires a meta-level reflexivity that allows the person to become aware of a transformation process" (Cunha, M. M. Gonçalves, Valsiner, Mendes, \& Ribeiro, in press). Performing change involves generalization of the change process into several life domains, which seems incompatible with mutual in-feeding. Thus, this reasoning too suggests that mutual in-feeding should occur relatively less frequently in these two types of IMs.

We examined three hypotheses in this study: (1) Poor-outcome cases present a higher percentage of IMs with RPMs; (2) the percentage of IMs with RPMs decreases throughout therapy in goodoutcome cases but not in poor-outcome cases; and (3) action, reflection, and protest IMs present more 
RPMs than reconceptualization and performing change IMs.

\section{Method}

Data for the current study were drawn from the Matos et al. (2009) study of IMs in narrative therapy. Relevant parts of that study's method-namely clients, therapist and therapy, measures, IM coding and reliability, and contrasting groups' constitution - are summarized here; please see Matos et al. (2009) for full details.

\section{Clients}

The client sample comprised 10 women with current experience of multidimensional intimate violence. They provided written consent after being informed of the research objectives and procedures. Clients ranged in age from 22 to 57 years. Four had no children and the remaining six had one to four children. Level of education varied from basic to postgraduate education, and occupations varied from rather unskilled to highly skilled. Seven clients were married, one was cohabitating with the partner, and the other two were dating (without cohabitation). By the end of psychotherapy, four clients had ended the relationship.

The abusive relationships in which these women were involved had lasted from 1 to 20 years. Four women were victimized for a long period of time ( $>5$ years), and for six the violence experience was briefer ( $<5$ years). Psychological violence was present in all the cases. Five clients were victims of both physical and sexual aggression.

\section{Therapist and Therapy}

Clients attended psychotherapy in a Portuguese university clinic, where they were seen in individual narrative therapy (White \& Epston, 1990). All clients were treated by the same female therapist, who at the time had a master's degree in psychology and 5 years of experience in psychotherapy with battered women. Psychotherapy was supervised to ensure therapist adherence to the narrative therapy model.

The therapy was developed from the narrative model of White and Epston (1990); see also White, 2007) and involved (1) externalization of problems; (2) identification of the cultural and social assumptions that support women's abuse; (3) identification of unique outcomes (or, as we prefer, IMs); (4) therapeutic questioning around these unique outcomes, trying to create a new, alternative narrative to the one that was externalized; and (5) consolidation of the changes through social validation, trying to make more visible the way change happened (see Matos et al., 2009, for a detailed description of the narrative therapy guidelines).

\section{Measures}

Brief Symptom Inventory (BSI; Derogatis \& Melisaratos, 1983). The BSI is a 53-item selfreport measurement of distress, with items rated on a 5-point Likert scale. Derogatis reported internal consistency estimates of $\alpha=.89$ and test-retest reliability of .90 for the GSI. We used the Portuguese adaptation by Canavarro (2007), which presents good psychometric characteristics (Cronbach's $\alpha$ for the nine symptom subscales ranges from .62-.80).

Severity of Victimization Rating Scale (SVRS). SVRS assesses abusive actions received (physical, psychological, and/or sexual), their frequency, and severity on a 3-point scale (low, medium, high); it is completed by the therapist based on the client's report.

Scale of beliefs about partner violence (Escala de Crenças Sobre Violência Conjugal [ECVC]; Matos, Machado, \& M. M. Gonçalves, 2000). The self-report ECVC evaluates clients' beliefs regarding partner violence. It contains 25 items, which are rated using a 5-point Likert scale. This scale has good reliability (Cronbach's $\alpha=.9$; C. Machado, Matos, \& M. M. Gonçalves, 2004).

Working Alliance Inventory (WAI; Horvath, 1982). This questionnaire assesses therapeutic alliance quality. It contains 36 items, which are rated on a 7-point Likert scale. The Portuguese version (P. P. Machado \& Horvath, 1999) presents good validity and reliability indicators (Cronbach's $\alpha=.95$ ).

\section{Procedure}

Outcome and alliance measures administration. BSI was administrated in Sessions $1,4,8,12$, and 16 and at 6-month follow-up. This study used the Global Severity Index (GSI) of the BSI, which considers responses to all items, because this is considered to be the best single predictor of level of distress (Derogatis, 1993). Like the BSI, SVRS was recorded every fourth session, starting with the first. EVCS was administrated in sessions 1 and 16 and at 6-month follow-up. WAI was administered in Sessions 4, 8, 12, and 16 and at 6-month follow-up; versions for client and observers 
(two independent observers coded recordings of sessions) were applied.

IM coding and reliability. IM coding was based on the IMCS (M. M. Gonçalves, Ribeiro et al., 2010a, 2010b) (Table I). First, each of three judges read the clinical files and watched the video recordings of each client's sessions in their entirety. The judges then independently listed the client's problems (themes from the dominant self-narrative that brought the client to therapy) and met to discuss their comprehension of the client's dominant selfnarrative. Following this, the client's dominant selfnarrative was consensually characterized in a way that remained faithful to the client's words. This procedure set the stage for the identification of IMs, insofar as they include every moment in which the client engaged in actions, thoughts, or emotions that were novel or different from the identified dominant self-narrative.

Next, the judges coded the IMs by viewing each session in video and noting the type and the salience of each IM as it appeared in the session. Salience was assessed by measuring the beginning and the end of each IM to the nearest second. The sessions were coded in the order they occurred. Session recordings were coded by trained judges: Judge A (Anita Santos, who was unaware of the outcomes) coded all the sessions; and Judge B (a team comprising Marlene Matos and another volunteer judge) coded only the sessions in which the outcome assessment instruments were applied (Sessions 1, 4, 8, 12, and 16 and 6-month follow-up).

Reliability indexes were computed on these sessions ( $30 \%$ of the entire sample). Interjudge agreement on overall salience was calculated as the time identified by both judges divided by the time identified by either judge. The percentage of agreement on overall IMs salience was $86 \%$. Reliability of distinguishing IM types, assessed by Cohen's $\kappa$, was .89 (based on a sample size of 547 IMs). Because of the high interjudge reliability, Matos et al. (2009) based their analyses on Judge A's coding. The results of applying the IMCS were reported previously by Matos et al. (2009) and were preliminary to this study's application of the RPM coding system.

RPM coding and reliability. Two judges participated in the RPM coding procedure (António P. Ribeiro and Tatiana Conde). At the time of coding, both were unaware of the outcome status of the cases.

Training for RPM coding began with reading the Manual for the Return to the Problem Coding System
(M. M. Gonçalves, Ribeiro, Santos, J. Gonçalves, \& Conde, 2009), along with theoretical papers and research reports that described relevant assumptions and major empirical findings. Next, the two judges coded RPMs in a workbook that included transcripts of all IMs from one psychotherapy case. This step was followed by a discussion of discrepancies with a group of other RPM judges in training and/or with a skilled RPM judge present. After this discussion, they coded a second workbook that included transcripts of all IMs from another psychotherapy case. Their codes were then compared with the codes of expert judges. New judges were required to achieve a Cohen's $\kappa$ higher than .75 before proceeding (both judges did).

As described in the RPCS manual (M. M. Gonçalves, Ribeiro, et al., 2009), RPMs are coded only when the dominant self-narrative is reasserted immediately after the IM, that is, within the same speaking turn or within the client's first speaking turn that follows the therapist's first intervention after the IM description (see the Appendix for an explanation of exceptions to these criteria), as in the following example:

Maybe I'll get what I want after all, I don't know [IM] ... but I feel weak, psychologically speaking ... as if me or someone inside me was incessantly saying 'You cannot, you will not be able to do it.' That's how I feel-weak, invariably sad, not thinking much of myself. [RPM]

RPMs coding comprised two sequential steps: (1) independent coding and (2) resolving disagreements through consensus. The judges independently coded the entire sample (126 sessions), analysing IMs coded by Matos et al. (2009) for the presence of RPMs, following the RPCS manual. The sessions were coded from video recording in the order they occurred. Reliability of identifying RPMs, assessed by Cohen's $\kappa$, was .93, based on the initial independent coding of a sample size of 1,596 IMs.

Throughout the coding process, the two judges met after coding each session and noted differences in their perspectives of the problems and in their RPM coding. When differences were detected, they were resolved through consensual discussion. During the collaborative meetings, the judges discussed the strengths of each other's coding and the criteria used to achieve them. Through this interactive procedure, the judges were able to integrate each other's strengths, which facilitated the coding of subsequent sessions (cf. Brinegar et al., 2006). Because we privileged false-negative over false-positive results, IMs on which the investigators could not reach an 
agreement were eliminated (Krause et al., 2007). The analysis was then based on the consensus between the two judges.

\section{Contrasting Groups' Constitution}

We used contrasting groups constructed by Matos et al. (2009), who distinguished a good-outcome group $(n=5)$ and a poor-outcome group $(n=5)$ based on two criteria. A good-outcome occurred when (1) there was an evolution toward a norelevant-symptom condition, as assessed by BSI, from the beginning to the end of therapy (based on a GSI cutoff score of $\leq 1.32$; Matos, 2006) and (2) simultaneously victimization by the partner ended or showed a very significant change from the beginning to the end of therapy, according to the client's report. Meeting this criterion required a significant change in victimization pattern, although the client might still experience relatively minor forms of violence (e.g., insulting, shouting) as well as a modification of episode frequency from continuous to occasional.

Good- and poor-outcome group demographics and alliance. Matos et al. (2009) reported no significant differences between the good- and poor-outcome groups in age, education level, relationship duration, victimization duration, initial scores on the GSI (symptoms) or the attitudes toward partner violence, as assessed by the ECVC. WAI results showed that the therapeutic alliance was high in both groups and in all the sessions evaluated, with a nominally significant difference in the perspective of one of the observers, according to whom the therapeutic alliance was better in the goodoutcome group at Session 4. There were no significant WAI differences in the perspective of the other observer, the clients, or the therapist.

IMs in good- and poor-outcome groups. Matos et al. (2009) reported that reconceptualization and performing change IMs were very rare in poor-outcome cases, and their salience was very low. The global salience of IMs was higher in the goodoutcome group; this disparity was entirely attributable to the differences in reconceptualization and performing change IMs. In the majority of goodoutcome cases, reconceptualization and performing change IMs emerged in the middle of the therapy and increased through the final phase, whereas they were almost absent throughout therapy in the pooroutcome cases.

\section{Results}

\section{RPMs in Good- and Poor-Outcome Groups: Analytic Strategy}

We used parametric tests ( $t$ test for Hypothesis 1 and two-way mixed analyses of variance [ANOVAs] for Hypotheses 2 and 3). We confirmed that our conclusions would not change when applying nonparametric tests, as proposed by Fife-Schaw (2006).

Significance levels were set at $\alpha=.05$. In the ANOVA, Greenhouse-Geisser $\varepsilon$-corrected $p$ values were reported to correct for violations of the sphericity assumption. According to Cohen (1988, 1992), effect sizes $f$ were computed for ANOVA effects and effect sizes $d$ for $t$-test mean differences.

The number of sessions varied from 12 to 16 in the good-outcome group $(M=14.60, S D=1.67)$ and from six to 16 in the poor-outcome group $(M=10.60, S D=4.34$; see Table II), but the mean number of sessions was not significantly different, $t(8)=1.93, p=.09$. Likewise, we found no differences in the frequency of IMs per session between the good-outcome $(M=14.53, S D=4.76)$ and the poor-outcome $(M=10.58, \quad S D=3.38)$ groups, $t(8)=1.51, p=.17$. Therefore, there was no need to use the number of coded sessions as a covariate.

\section{Hypothesis 1: The Emergence of RPMs in Good- and Poor-Outcome Groups}

Consistent with our hypothesis, RPMs were less frequent in the good-outcome group $(M=16.20$, $S D=4.82)$ than in the poor-outcome group $(M=$ $42.00, S D=21.76$ ), a statistically significant difference, $t(8)=-2.59, p=.03$, effect size $d=1.64$.

Because the number of IMs varied substantially across cases, we also computed the percentage of IMs with RPMs (frequency of IMs with RPMs/total frequency of $\mathrm{IMs} \times 100)$. The poor-outcome group $(M=38.94, S D=13.15)$ had a significantly higher percentage of IMs with RPMs than did the goodoutcome group $(M=7.84, S D=1.51), t(8)=-5.25$, $p=.001, d=3.32$.

Table II. Number of Sessions in Good- and Poor-Outcome Groups

\begin{tabular}{lcllc}
\hline \multicolumn{2}{l}{ Good-outcome group } & & \multicolumn{2}{c}{ Poor-outcome group } \\
\cline { 1 - 2 } \cline { 5 - 5 } Case & No. sessions & & Case & No. sessions \\
\hline 1 & 14 & & 6 & 10 \\
2 & 15 & & 7 & 6 \\
3 & 12 & & 8 & 7 \\
4 & 16 & & 9 & 16 \\
5 & 16 & & 10 & 14 \\
\hline
\end{tabular}




\section{Hypothesis 2: The Evolution of RPMs in Good- and Poor-Outcome Groups}

Contrary to our hypothesis, the percentage of IMs with RPMs did not change from the first to the last session. The poor-outcome group had a higher percentage of IMs with RPMs than did the goodoutcome group in both their first $\left(M_{\mathrm{good}}=11.36\right.$, $\left.S D=7.34 ; \quad M_{\text {poor }}=47.03, \quad S D=35.47\right)$ and last $\left(M_{\text {good }}=4.32, \quad S D=4.04 ; \quad M_{\text {poor }}=40.85, \quad S D=\right.$ 20.45) sessions. In a two-way mixed ANOVA with group as the between-subjects factor and session as the within-subject factor, the main effect of group was significant, $F(1,8)=9.82, p=.01$, effect size $f=1.11$; however, the main effect of session was not, $F(1,8)=1.04, p=.34, f=.11$, nor was the Session $\times$ Group interaction, $F(1,8)=.00, p=.95, f=.03$.

\section{Hypothesis 3: The Occurrence of RPMs in Different Types of IMs}

The five types of IMs showed greatly different likelihood of including RPMs in a pattern that partially supported Hypothesis 3 (Table III). A two-way mixed ANOVA with group as the between-subjects factor and the type of IM as the within-subject factor found a significant main effect of type of IM, $F(2.19,17.54)=19.22, p=.000$, $f=1.55$. Pairwise comparisons revealed that RPMs were less likely in reconceptualization than in reflection and protest IMs and less likely in performing change than in reflection, protest, and reconceptualization IMs. Consistent with Hypothesis 3, the likelihood of RPMs in reconceptualization and performing change IMs was significantly lower than in reflection or in protest IMs. Contrary to Hypothesis 3, however, the likelihood of RPMs in action IMs was not significantly different than in reconceptualization or in performing change IMs.

As Table III shows, the profile of likelihoods was similar in the good- and poor-outcome groups. The main effect of group was not significant, $F(1,8)=$

Table III. Percentage (Mean \pm Standard Deviation) of Return-tothe-Problem Markers in Different Types of Innovative Moments (IMs)

\begin{tabular}{lcc}
\hline IM & $\begin{array}{c}\text { Good-outcome } \\
\text { group }(n=5)\end{array}$ & $\begin{array}{c}\text { Poor-outcome } \\
\text { group }(n=5)\end{array}$ \\
\hline Action & $16.76(18.97)$ & $11.28(11.02)$ \\
Reflection & $44.09(14.00)$ & $45.30(13.97)$ \\
Protest & $25.16(7.59)$ & $35.07(13.85)$ \\
Reconceptualization & $12.74(4.31)$ & $5.45(7.67)$ \\
Performing change & $1.25(2.80)$ & $2.90(5.44)$ \\
\hline
\end{tabular}

$0.00, p=1, f=.00$, nor was the Type of IM $\times$ Group interaction, $F(2.19,17.54)=0.75, p=.50, f=.31$.

\section{Discussion}

In accord with our first hypothesis, IMs were much more likely to be followed by a return to the dominant narrative in the five poor-outcome cases than in the five good-outcome cases. Even though the groups had similar levels of symptom severity at intake, they showed dramatically different percentages of IMs containing RPMs. This observation is consistent with the theoretical suggestion that mutual in-feeding between the dominant self-narrative and IMs can interfere with therapeutic progress or at least mark the lack of progress (M. M. Gonçalves, Matos et al., 2009).

Contrary to our second hypothesis, that the different likelihood of RPMs would occur only later in therapy, the lower likelihood of RPMs in the good-outcome group was apparent in the first as well as the last session. Perhaps clients in these groups, despite their similar levels of symptom severity, entered therapy at different stages of change. Stage models of psychological change suggest that certain tasks have to be accomplished before others can be undertaken. Two prominent examples of such models are the assimilation model (Honos-Webb \& Stiles, 1998; Stiles, 2002; Stiles et al., 1990) and the transtheoretical model of behavior change (TTM; Napper et al., 2008; Prochaska \& DiClemente, 1982; Prochaska \& Norcross, 2001). According to the assimilation model, clients' incremental assimilation of their problematic experiences proceeds in eight stages (Stiles, 2002), from complete dissociation to smooth integration of the formerly nondominant (problematic) voices into the self. According to the TTM, change proceeds through five stages: precontemplation, contemplation, preparation, action, and maintenance. Studies framed within each of these models have suggested that clients entering therapy at earlier stages are less likely to have successful outcomes than those entering at later stages (Emmerling \& Whelton, 2009; Honos-Webb, Stiles, Greenberg, \& Goldman, 1998; Stiles, 2006). Perhaps clients in this study's poor-outcome group entered therapy at lower stages of the change process (e.g., precontemplation in the TTM sequence or unwanted thoughts/avoidance in the assimilation sequence), whereas those in good-outcome cases entered therapy at higher stages. Alternatively, perhaps clients from the good-outcome group entered treatment with more psychological and social resources or were more involved in therapy (although there were no significant between-group differences in age, education level, relationship 
duration, victimization duration, or initial scores on symptomatology as assessed by the BSI or the attitudes toward partner violence, as assessed by the ECVC). Unfortunately, we have no data that allow us to distinguish conclusively among these possibilities.

Finding a lower incidence of RPMs in reconceptualization and performing change IMs than in reflection and protest IMs is congruent with theoretical assumptions (see M. M. Gonçalves, Matos et al., 2009), corroborating reconceptualization and performing change as markers of sustained therapeutic change (Hypothesis 3). Action IMs were intermediate: less likely to contain RPMs than reflection and protest and more likely to contain RPMs than reconceptualization and performing change. Action IMs are overt and tend to be more visible to the client and others than protest and reflection IMs. Perhaps they are experienced as "real proofs that I am changing" and consequently less vulnerable to mutual in-feeding.

Several limitations should be noted. Confidence in the generality of our findings about psychotherapeutic failure is limited by the small size of our sample and its restriction to victims of intimate violence. Application of our new method for coding RPMs to other samples may clarify whether RPMs are also associated with unsuccessful psychotherapy of other types and in other groups.

Practitioners are likely to encounter the mutual infeeding process at some point in their clinical practice, and RPMs might offer information useful for identifying and addressing unproductive stagnation of the therapeutic process (Santos et al., 2010). Understanding RPMs may help therapists deal with ambivalence in therapy. Identifying these processes opens the option to act upon them, inviting clients to position themselves in new ways and resolving therapeutic impasses.

We did not assess clients' stage of change (e.g., according to the APES or the TTM), so we could not assess whether this accounted for the group differences in RPMs at the beginning of treatment. In future studies, evaluating clients' stage of change at the beginning of therapy would contribute to understanding this possibility. When therapists try to stimulate or amplify IMs in ways that do not match clients' stage of change, they may unintentionally contribute to the oscillatory cycle between the IMs and the problem (Santos et al., 2010). For example, if therapists respond to clients' return to the dominant self-narrative by trying to convince them that they are changing, clients may feel misunderstood, invoking a "strong reactance on the part of the client, often hardening the client's stuck position" (Engle \& Arkowitz, 2008, p. 390). Engle and Arkowitz sug- gested that "therapists need to monitor their frustration, resist the temptation to 'help' the client by pushing for change, and to direct his or her efforts toward an understanding of what it is in the client's experience that prevents easy change" (p. 391).

RPMs may not always represent therapeutic stagnation. In studies of two good-outcome cases, Brinegar et al. (2006) identified the rapid cross-fire phenomenon: an alternation of opposing expressions that appears to qualify as an RPM. They identified rapid cross-fire as a substage in the successful assimilation of specific problematic experiences in those cases, although importantly it occurred in only a few sessions during the middle of treatment, in contrast to its continued presence throughout treatment in our poor-outcome cases. Nevertheless, the possibility that RPMs may sometimes signal or contribute to therapeutic movement deserves further study.

Mutual in-feeding is an interpersonal process and needs to be understood in the interpersonal context in which it occurs: the intersubjective field created in all interactions between the therapist and the client (Engle \& Arkowitz, 2008). According to Engle and Arkowitz, "Therapists can facilitate the resolution of resistant ambivalence by creating insession exercises that increase awareness and integration of disowned aspects of the self" (p. 393), in the context of a safe and accepting relationship. Focused theory-building case studies (Stiles, 2009) could yield a deeper understanding of how therapists contribute to maintaining or overcoming mutual in-feeding.

\section{Appendix: Some Subtleties of RPM Coding}

Normally, an RPM is coded only if the return takes place within the same speaking turn or in the client's first speaking turn that follows the therapist's first intervention after the IM. However, two sorts of therapist response are not considered as interventions for this purpose:

\section{Minimal Encouragers}

We do not consider minimal encouragers, such as minimal verbal utterances (e.g., "Umm" and "Uh-huh"), or repetition of key words and direct restatement as the therapist's first interventions, as in the following example:

Client: Lately, perhaps since I moved ... about 2 weeks ago, I've been feeling better. [IM]

Therapist: Uh-huh. [Minimal encourager; not to be considered as the first therapist intervention] Client: I moved because my apartment was too 
expensive ...this new one is cheaper and it's closer to my job.

Therapist: So you've been feeling better, is that right? [Should be considered as the therapist's first intervention after IM description]

Client: Not really, I keep crying all the time! [Client's first speaking turn after therapist's first intervention, representing an RPM]

By the same token, we do not consider the client's minimal verbal utterances (e.g., "Umm" and "Uhhuh") as the first speaking turn after the therapist first intervention, as in the following example:

Client: Lately, perhaps since I moved ... about 2 weeks ago, I've been feeling better. [IM]

Therapist: I have been noticing that you are different. [Therapist's first intervention]

Client: Uh-huh. [Minimal encourager; not to be considered as client's first speaking turn after therapist's first intervention]

Therapist: You seem more active, happier.

Client: Although I seem happier, I don't I feel happier! Although I don't cry as much as I used to, the problems don't seem to set apart! [Should be considered as client's first speaking turn after therapist's first intervention, representing an RPM]

\section{Therapist's Intervention Not Centred on IM Content}

We only consider the client's first speaking turn that follows the therapist's first intervention after the IM description, when this intervention is centred on the IM's content. Hence, we do not consider an RPM when the therapist intervention clearly invites the client to speak about the problem, as in the following example:

Client: Although I still find it hard to get going in the mornings, I kind of don't try to sweep away things that much anymore, that's I guess one major change. [IM]

Therapist: You said it's hard to get going. Is the sadness more intense in the mornings? [Therapist's question clearly invites client to speak about the problem]

Client: Yes, indeed. [Client's first speaking turn that follows the therapist's first intervention after IM description; should not be coded as an RPM]

\section{Acknowledgements}

This study was supported by Portuguese Foundation for Science and Technology by the Grant PTDC/ PSI/72846/2006 (Narrative Processes in Psychotherapy) and the PhD Grant SFRH/BD/46189/2008.

\section{Notes}

1 The concept of IMs is a methodological realization of the concept of unique outcome proposed by White and Epston (1990). See M. M. Gonçalves, Matos et al. (2009) for a discussion of this topic.

2 Instead of using frequency as a measure of the IMs, we prefer to use salience, because frequency is simply the emergence of a given IM, giving no information about how long therapists and clients were talking about it. Therefore, we consider that salience is a more direct indicator of narrative elaboration.

\section{References}

Arkowitz, H., \& Engle, D. (2007). Understanding and working with resistant ambivalence in psychotherapy. In S. G. Hofmann \& J. Weinberg (Eds.), The art and science of psychotherapy (pp. 171-190). New York: Routledge.

Brinegar, M. G., Salvi, L. M., Stiles, W. B., \& Greenberg, L. S. (2006). Building a meaning bridge: Therapeutic progress from problem formulation to understanding. Fournal of Counseling Psychology, 53, 165-180.

Canavarro, M. C. (2007). Inventário de Sintomas Psicopatológicos (BSI): Uma revisão crítica dos estudos realizados em Portugal. In M. R. Simões, C. Machado, M. M. Gonçalves \& L. S. Almeida (Eds.), Avaliação psicológica: Instrumentos validados para a população Portuguesa [Psychological assessment: Validated instruments for the Portuguese population] (Vol. III (pp. 305-331). Coimbra, Portugal: Quarteto.

Cohen, J. (1988). Statistical power analysis for behavioral science. New York: Erlbaum.

Cohen, J. (1992). A power primer. Psychological Bulletin, 112, 155159.

Cunha, C., Gonçalves, M. M., Valsiner, J., Mendes, I., \& Ribeiro, A. P. (in press). Rehearsing renewal of identity: Re-conceptualization on the move. In M.C. Bertau, M.M. Gonçalves, \& P. Raggat (Eds.). The development of the dialogical self. Advances in cultural psychology (series editor: Jaan Valsiner). Charlotte, NC: Information Age Publications.

Derogatis, L. R. (1993). BSI-Brief Symptom Inventory. Administration, scoring, and procedures manual (4th ed.). Minneapolis, $\mathrm{MN}$ : National Computer Systems.

Derogatis, L. R., \& Melisaratos, N. (1983). The Brief Symptom Inventory: An introductory report. Psychological Medicine, 13, 595-605.

Ecker, B., \& Hulley, L. (2000). The order in clinical disorders: Symptom coherence in depth-oriented brief therapy. In R. A. Neimeyer \& J. D. Raskin (Eds.), Construction of disorder: Meaning-making frameworks for psychotherapy (pp. 63-89). Washington, DC: American Psychological Association.

Emmerling, M., \& Whelton, W. (2009). Stages of change and the working alliance in psychotherapy. Psychotherapy Research, 19, $1-12$.

Engle, D., \& Arkowitz, H. (2008). Viewing resistance as ambivalence: Integrative strategies for working with resistant ambivalence. Fournal of Humanistic Psychology, 48, 389-412.

Engle, D., \& Holiman, M. (2002). A gestalt-experiential perspective on resistance. Fournal of Clinical Psychology, 58, 175-183. 
Feixas, G., Sánchez, V., \& Gómez-Jarabo, G. (2002). La resistencia en psicoterapia: El papel de la reactância, la construcción del sí mismo y el tipo de demanda [Resistance in psychotherapy: The role of reactance, self-construction, and the type of request]. Análisis y Modificación de Conducta, 28(118), 235-286.

Fernandes, E., Senra, E., \& Feixas, G. (2010). Terapia construtivista centrada em dilemas implicativos [Constructivist psychotherapy focused on implicative dilemmas]. Braga, Portugal: Psiquilíbrios.

Fife-Schaw, C. (2006). Levels of measurement. In G. M. Breakwell, S. Hammond, C. Fife-Schaw \& J. A. Smith (Eds.), Research methods in psychology (3rd ed., pp. 50-63). London: Sage.

Gonçalves, M. M., Matos, M., \& Santos, A. (2009). Narrative therapy and the nature of "innovative moments" in the construction of change. Fournal of Constructivist Psychology, 22, 1-23.

Gonçalves, M. M., Mendes, I., Ribeiro, A. P., Angus, L., \& Greenberg, L. (2010). Innovative moments and change in emotion-focused therapy: The case of Lisa. Fournal of Constructivist Psychology, 23, 267-294.

Gonçalves, M. M., \& Ribeiro, A. P. (in press). Narrative processes of innovation and stability within the dialogical self. In H. J. M. Hermans \& T. Gieser (Eds.), Handbook of dialogical self theory. Cambridge: Cambridge University Press.

Gonçalves, M. M., Ribeiro, A. P., Matos, M., Mendes, I., \& Santos, A. (2010a). The innovative moments coding system: A coding procedure for tracking changes in psychotherapy. In S. Salvatore \& J. Valsiner, J. T. Simon \& A. Gennaro (Eds.), YIS: Yearbook of idiographic science. Volume 2 (pp. 107-130). Rome: Firera \& Liuzo.

Gonçalves, M. M., Ribeiro, A. P., Matos, M., Mendes, I., \& Santos, A. (2010b). Tracking novelties in psychotherapy research process: The innovative moment coding system. Manuscript in preparation.

Gonçalves, M. M., Ribeiro, A. P., Santos, A., Gonçalves, J., \& Conde, T. (2009). Manual for the return to the problem coding system-version 2. Unpublished manuscript, University of Minho, Braga, Portugal.

Gonçalves, M. M., Santos, A., Salgado, J., Matos, M., Mendes, I., Ribeiro, A. P., ... Gonçalves, J. (2010). Innovations in psychotherapy: Tracking the narrative construction of change. In J. D. Raskin, S. K. Bridges \& R. Neimeyer (Eds.), Studies in meaning 4: Constructivist perspectives on theory, practice, and social justice (pp. 29-64). New York: Pace University Press.

Hayes, A. M., Laurenceau, J.-P., Feldman, G. C., Strauss, J. L., \& Cardaciotto, L. A. (2007). Change is not always linear: The study of nonlinear and discontinuous patterns of change in psychotherapy. Clinical Psychology Review, 27, 715-723.

Hermans, H. J. M. (1996). Opposites in a dialogical self: Constructs as characters. fournal of Constructivist Psychology, 9, 1-26.

Hermans, H. J. M., \& Hermans-Jansen, E. (1995). Self-narratives: The construction of meaning in psychotherapy. New York: Guilford.

Honos-Webb, L., \& Stiles, W. B. (1998). Reformulation of assimilation analysis in terms of voices. Psychotherapy, 35, 2333.

Honos-Webb, L., Stiles, W. B., Greenberg, L. S., \& Goldman, R. (1998). Assimilation analysis of process-experiential psychotherapy: A comparison of two cases. Psychotherapy Research, 8, 264-286.

Horvath, A. O. (1982). Users' manual of the Working Alliance Inventory. Unpublished manuscript, Simon Fraser University, Burnaby, British Columbia.
Josephs, I. E., \& Valsiner, J. (1998). How does autodialogue work? Miracles of meaning maintenance and circumvention strategies. Social Psychology Quarterly, 61, 68-83.

Kelly, G. A. (1955). The psychology of personal constructs. New York: Norton.

Krause, M., de la Parra, G., Arístegui, R., Dagnino, P., Tomicic, A., Valdés, N., ... Ben-Dov, P. (2007). The evolution of therapeutic change studied through generic change indicators. Psychotherapy Research, 17, 673-679.

Machado, C., Matos, M., \& Gonçalves, M. M. (2004). Escala de crenças sobre a violência conjugal (ECVC). In L. S. Almeida, M. R. Simões, C. Machado, \& M. M. Gonçalves (Eds.), Avaliação psicológica: Instrumentos validados para a população Portuguesa [Psychological assessment: Validated instruments for the Portuguese population] (Vol. II, pp. 127-140). Coimbra, Portugal: Quarteto.

Machado, P. P., \& Horvath, A.O. (1999). Inventário da aliança terapêutica--WAI. In M. R. Simões, M. M. Gonçalves \& L. S. Almeida (Eds.), Testes e provas psicológicas em Portugal [Tests and psychological instruments in Portugal] (Vol. II, pp. 87-94). Braga, Portugal: APPORT/SHO.

Mahoney, M. (1991). Human change processes: The scientific foundations of psychotherapy. New York: Basic Books.

Matos, M. (2006). Violência nas relações de intimidade. Estudo sobre a mudança psicoterapêutica da mulher [Violence in intimate relationships: A research about the psychotherapeutic change in women]. Unpublished doctoral dissertation, University of Minho, Braga, Portugal.

Matos, M., Machado, C., \& Gonçalves, M. M. (2000). ECVCEscala de crenças sobre a violência conjugal [Scale of beliefs of marital violence]. Unpublished manuscript, University of Minho, Braga, Portugal.

Matos, M., Santos, A., Gonçalves, M. M., \& Martins, C. (2009). Innovative moments and change in narrative therapy. Psychotherapy Research, 19, 68-80.

McCarthy, K., \& Barber, J. P. (2007). Review of ambivalence in psychotherapy. Psychotherapy Research, 17, 504-506.

Mendes, I., Ribeiro, A. P., Angus, L., Greenberg, L., Sousa, I., \& Gonçalves, M. M. (in press). Narrative change in emotionfocused therapy: How is change constructed through the lens of the Innovative Moments Coding System? Psychotherapy Research.

Napper, L. E., Wood, M. M., Jaffe, A., Fisher, D. G., Reynolds, G. L., \& Klahn, J. A. (2008). Convergent and discriminant validity of three measures of stage of change. Psychology of Addictive Behaviors, 22, 362-371.

Osatuke, K., Glick, M. J., Gray, M. A., Reynolds, D. J., Jr., Humphreys, C. L., Salvi, L. M., \& Stiles, W. B. (2004). Assimilation and narrative: Stories as meaning bridges. In L. Angus \& J. McLeod (Eds.), Handbook of narrative and psychotherapy: Practice, theory, and research (pp. 193-210). Thousand Oaks, CA: Sage.

Osatuke, K., Mosher, J. K., Goldsmith, J. Z., Stiles, W. B., Shapiro, D. A., Hardy, G. E., \& Barkham, M. (2007). Submissive voices dominate in depression: Assimilation analysis of a helpful session. Fournal of Clinical Psychology, 63, 153164.

Osatuke, K., \& Stiles, W. B. (2010). Dialogical self and depression: The assimilation model perspective. Manuscript submitted for publication.

Perls, F. S. (1969). Gestalt therapy verbatim. Lafayette, CA: Real People Press.

Polkinghorne, D. E. (2004). Narrative therapy and postmodernism. In L. E. Angus \& J. McLeod (Eds.), The handbook of narrative and psychotherapy: Practice, theory and research (pp. 5368). Thousand Oaks, CA: Sage. 


\section{M. M. Gonçalves et al.}

Prochaska, J. O., \& DiClemente, C. (1982). Transtheoretical therapy: Toward a more integrative model of change. Psychotherapy: Theory, Research and Practice, 19, 276-288.

Prochaska, J. O., \& Norcross, J. (2001). Stages of change. Psychotherapy, 38, 443-448.

Ribeiro, A. P., \& Gonçalves, M. M. (2010). Innovation and stability within the dialogical self: The centrality of ambivalence. Culture $\&$ Psychology, 16, 116-126.

Ribeiro, A. P., Gonçalves, M. M., \& Santos, A. (in press). Innovative moments in psychotherapy: From the narrative outputs to the semiotic-dialogical processes. In S. Salvatore, J. Valsiner, S. Strout \& J. Clegg (Eds.), YIS: Yearbook of idiographic science. Volume 3. Rome: Firera.

Rice, L. N., \& Saperia, E. P. (1984). Task analysis and the resolution of problematic reactions. In L. N. Rice \& L. S. Greenberg (Eds.), Patterns of change (pp. 29-66). New York: Guilford.

Santos, A., \& Gonçalves, M. M. (2009). Innovative moments and change processes in psychotherapy: An exercise in new methodology. In J. Valsiner, P. C. M. Molenaar, M. C. D. P. Lyra \& N. Chaudhary (Eds.), Dynamic process methodology in the social and developmental sciences (pp. 493-526). New York: Springer.

Santos, A., Gonçalves, M. M., \& Matos, M. (2010). Innovative moments and poor-outcome in narrative therapy. Counselling and Psychotherapy Research. DOI: 10.1080/1473314090339 8153.

Santos, A., Gonçalves, M. M., Matos, M., \& Salvatore, S. (2009). Innovative moments and change pathways: A good outcome case of narrative therapy. Psychology and Psychotherapy: Theory, Research and Practice, 82, 449-466.
Stiles, W. B. (1999). Signs and voices in psychotherapy. Psychotherapy Research, 9, 1-21.

Stiles, W. B. (2002). Assimilation of problematic experiences. In J. C. Norcross (Ed.), Psychotherapy relationships that work: Therapist contributions and responsiveness to patients (pp. 357365). New York: Oxford University Press.

Stiles, W. B. (2006). Assimilation and the process of outcome: Introduction to a special section. Psychotherapy Research, 16, 389-392.

Stiles, W. B. (2009). Logical operations in theory-building case studies. Pragmatic Case Studies in Psychotherapy, 5, 9-22.

Stiles, W. B., Elliott, R., Llewelyn, S. P., Firth-Cozens, J. A., Margison, F. R., Shapiro, D. A., \& Hardy, G. (1990). Assimilation of problematic experiences by clients in psychotherapy. Psychotherapy, 27, 411-420.

Stiles, W. B., Osatuke, K., Glick, M. J., \& Mackay, H. C. (2004). Encounters between internal voices generate emotion: An elaboration of the assimilation model. In $\mathrm{H}$. H. Hermans \& G. Dimaggio (Eds.), The dialogical self in psychotherapy (pp. 91107). New York: Brunner-Routledge.

Swann, W. B. (1987). Identity negotiation: Where two roads meet. fournal of Personality and Social Psychology, 53, 1038-1051.

Valsiner, J. (2002). Forms of dialogical relations and semiotic autoregulation within the self. Theory and Psychology, 12, 251265.

White, M. (2007). Maps of narrative practice. New York: Norton.

White, M., \& Epston, D. (1990). Narrative means to therapeutic ends. New York: Norton.

Zimmerman, J. L., \& Dickerson, V. C. (1994). Using a narrative metaphor: Implications for theory and clinical practice. Family Process, 33, 233-246. 